\title{
OUTCOME OF PEDIATRIC PYELOPLASTY IN RENAL UNITS WITH SPLIT RENAL FUNCTION LESS THAN $20 \%$
}

\author{
By
Gamal Ibrahim Selmy*, El- Sayed Mohamed Salih*, Mohsen Salah El- Din Zykri**, Ibrahim Abd El-Kawey Abd El-Maksoud*

Department of Urology* and Nuclear Medicine**, Al-Azhar Faculty of Medicine

E-mail: i.urologist@hotmail.com

\begin{abstract}
Background: Prenatally diagnosed, hydronehprosis does not mean presence of decompensated obstruction and spontaneously improvement or resolution can occur postnatally. If obstruction persists, the split renal function (SRF) of the diseased kidney will dramatically decrease, and surgical intervention will be necessary.
\end{abstract}

Objective: Evaluation of outcome of pyeloplasty in children with ureteropelvic junction obstruction (UPJO) in renal unit with split function less than $20 \%$ and to asses renal function recoverability.

Patients and Methods: Cohort (historical and concurrent) study included 88 patients with UPJO with split renal function (SRF) $<20 \%$. Preoperative patient was investigated by abdominopelvic ultrasound, magnetic resonance urography (MRU) or computerized tomography and renal isotope scan. Split renal function and $T$ $1 / 2$.Preoperative and postoperative were compared. Results of the procedure were evaluated by clinical examination, abdomino-pelvic ultrasound after one month. Urine analysis with culture and sensitivity and renal isotope scan after 6 months.

Results: Our study included 88 patients divided into two groups according to SRF (group 1, SRF $>20 \%$ and group 2, SRF $<20 \%$ ). Mean preoperative SRF was $31.34 \pm 15.27 \%$ in all cases, $41.79 \pm 7.03 \%$ in group 1 and $13.06 \pm 4.90 \%$ in group 2 , which increased postoperatively to $38.35 \pm 15.61 \%, 46.86 \pm 8.43 \%$ and $20.81 \pm$ $7.67 \%$ respectively and this improvement was highly significant. Group 2 included 9 patient with SRF < $10 \%$, mean preoperative SRF was $6.21 \pm 2.26 \%$ which increased preoperatively to $15.04 \pm 7.09 \%$, also in the remaining 23 cases, mean preoperative SRF was $15.74 \pm 2.30 \%$ increased postoperatively to $23.07 \pm$ $6.75 \%$.

Conclusion: Poorly functioning renal unit with SRF $<20 \%$, can show functional improvement and recoverability, so in these renal units, we should not have to rush to nephrectomy and instead of that we can proceed to pyeloplasty.

Key words: Ureteropelvic junction obstruction; Pyeloplasty; split renal function, Pediatric.

\section{INTRODUCTION}

Ureteropelvic junction obstruction (UPJO) is considered one of the most common causes of hydronehprosis in pediatric (Kim et al., 2010). Indications for intervention in kidney with UPJO include the following Split renal function $(\mathrm{SRF})<40 \%$, Deterioration of split renal function of $>10 \%$ in serial studies, impaired drainage after the injection of laxis, increased anteroposterior diameter on serial ultrasound and Grade III and IV dilatation according to the Society for Fetal Urology (Radmayr et al., 2019). The intervention for poorly functioning kidneys has no clear protocol which can be used as a guideline. The traditional 
intervention is nephrectomy but recently, there were studies which recommend pyeloplasty even with $\mathrm{SRF}<10 \%$ as these kidneys shows significant improvement (Lone et al., 2017).

The present work aimed to evaluate pyeloplasty outcome in children with pelvi-ureteric junction obstruction in renal unit with split renal function less than $20 \%$ and assessment of renal function recoverability.

\section{PATIENTS AND METHODS}

Cohort (historical and concurrent) study was carried out at Al-Azhar university hospitals after approval of study protocol by local ethical committee. Prospective cases included 20 patients and retrospective cases including patients who underwent pyeloplasty from 2011 to 2017. Patients were divided into 2 groups according to Split Function:

Group1: SF > $20 \%$.

Group 2: SF from $0 \%$ to $20 \%$.

\section{Inclusion criteria:}

Our study included pediatric patients with unilateral, single-system hydronehprosis due to UPJO and a normal contralateral kidney.

\section{Exclusion criteria:}

Bilateral UPJO, Recurrent cases and associated anomalies (vesicoureteral reflux (VUR), solitary kidney, posterior urethral valve) were excluded from the study.

Preoperative evaluation include the following: History, clinical examination, Laboratory investigation: Routine preoperative investigation including: (Complete Blood Count, Bleeding profile including prothrombin time, prothrombin concentration, and Fasting blood glucose level, liver function tests, serum Creatinine and urine analysis) and Imaging studies in form of Pelvi abdominal US. Magnetic resonance urography (MRU) or computerized tomography and renal isotope scan: looking for split renal function and $\mathrm{T} 1 / 2$. degree of hydronehprosis according to the classification of the Society for Fetal Urology (SFU), with grade (0) indicating a normal kidney with an intact renal sinus, grade (1) indicating a slightly dilated renal pelvis without caliectasis, grade (2) indicating a moderately dilated renal pelvis with mild caliectasis, grade (3) indicating a large renal pelvis and dilated calices, and grade (4) indicating a large renal pelvis with large dilated calices (Fernbach et al., 1993). Renal isotope scan was done using $99 \mathrm{~m}$ Diethylenetriaminepentaacetic acid (DTPA). Adequate hydration either oral or parenteral is very important prior to study. SRF was measured by the calculation of accumulated tracer in each kidney between 1 and 3 minutes after radionuclide injection. Renal and background regions of interest (ROIs) should be drawn on all acquisition data; background (ROIs) included the upper, outer and lower aspects of the kidney. Background activity was subtracted and the net counts within each kidney were expressed as a percent of total renal counts. Kidney function was classified as good when SRF was $\geq 40 \%$ impaired when it was $<40 \%$ and poor when it was $<20 \%$. Intravenous laxis was injected 20 minutes after radionuclide injection; dose of furosemide is $0.5 \mathrm{mg} / \mathrm{kg}$ for infants during the first year of life, and for older 
children $1 \mathrm{mg} / \mathrm{kg}$, and $\mathrm{t}^{1 / 2}>20$ min with continuously rising curve was defined as obstructed drainage. All patients in our study underwent Anderson-Hynes dismembered pyeloplasty (except four cases underwent $\mathrm{Y}-\mathrm{V}$ plasty) under general and caudal anesthesia. Early postoperative evaluation: Including: Vital signs, abdominal tenderness and rigidity, Drain output, Post-operative pain and early post-operative complications e.g. fever, infection and leakage. KUB after 24 hours to ensure that DJ in place .Catheter was removed in 2 nd postoperative day if there was no drain output, and then drain removed in 5th day. The postoperative complications were classified according to the Clavien system (Dindo et al 2008). Results of the procedure evaluated by: Clinical examination, Abdomino-pelvic ultrasound after one month. Urine analysis with culture and sensitivity and Renal isotopic scan (after 6 months).A reduction of SRF of more than $5 \%$ of the previous value was considered as deterioration, an increase of more than 5\% was defined as improvement, and changes within 5\% were considered as preservation. Criteria for successful outcome: Success was defined on the basis of either improvement in symptoms, improvement in drainage on postoperative Tc-99m DTPA renography, regression of degree of obstruction and/or improvement or preservation in renal function on renal scan. Data were collected, revised, coded and entered to the Statistical Package for Social Science (IBM SPSS) version 23. The distribution of quantitative data was tested by Kolmogorov-Smirnov test of normality. So, the quantitative data were presented as mean, standard deviations and ranges when parametric while nonparametric were presented as median with inter-quartile range (IQR). Also, qualitative variables were presented as number and percentages.

The comparison between groups regarding qualitative data was done by using Chi-square test and/or Fisher exact test when the expected count in any cell found less than 5. The comparison between two independent groups with quantitative data and parametric distribution was done by using Independent t-test while with nonparametric distribution was done by using Mann-Whitney test. The comparison between two paired groups with quantitative data and parametric distribution was done by using Paired ttest. The confidence interval was set to 95\% and the margin of error accepted was set to $5 \%$. P-value $<0.05$ was considered significant.

\section{RESULTS}

Our study included 88 patients. Patients divided into two groups: Group 1 included 56 patients and group 2 included 32 patients. Median age was 2.5 years (1 year in group 1 and 6 years in group 2), number of males was 66 (40 in group 1 and 26 in group 2), female patients were 22 (16 in group 1 and 6 in group 2). Left side affection was in $59.1 \%$ of cases (34 in group 1 and 18 in group 2). Right side affection was in $40.9 \%$ of cases (22 in group 1 and 14 in group 2). 
As regard clinical presentation of patient in our study was as follow: 30 cases were diagnosed antenatal (23 in group 1 and 7 in group 2), 18 cases were discovered accidentally (10 in group 1 and 8 in group 2), 31 cases were presented with loin pain (20 in group 1 and 11 in group 2) and 9 cases were presented with abdominal swelling (3 in group 1 and 6 in group2). As regard preoperative radiological data, degree of obstruction was as follow: 3 cases with mild hydronehprosis (all of them in group 1), 38 cases with moderate hydronehprosis (32 cases in group 1 and 6 cases in group 2) and 47 cases with marked hydronehprosis (21 cases in group 1 and 26 case in group 2). Most of cases in group 2 were presented with marked hydronehprosis. Mean over all
Preoperative SRF\% was $31.34 \pm 15.27$ $(41.79 \pm 7.03$ in group 1 and $13.06 \pm$ 4.90 in group 2).

All cases in our study underwent dismembered pyeloplasty except 4 cases underwent Y-V plasty (all of them in group 2). All cases underwent internal stent fixation which was removed one month later. All over success rate was $95.5 \%$ (98.2\% in group 1 and $90.6 \%$ in group 2). As regard improvement of SRF, mean postoperative SRF for all cases was $38.35 \pm 15.61$ (p-value 0.000). In group 1 , it was $46.86 \pm 8.43$ (p-value 0.000 ) and in group 2 was $20.81 \pm 7.67$ (p-value 0.000). There was no significant difference in improvement in both groups as regard SRF, T- half and degree of obstruction (Table 1).

Table (1): Comparison between group 1 and group 2 regarding postoperative data

\begin{tabular}{|c|c|c|c|c|}
\hline \multirow{2}{*}{\multicolumn{2}{|c|}{\begin{tabular}{|l} 
Parameters \\
Groups
\end{tabular}}} & Group 1 & Group 2 & \multirow{2}{*}{ P-value } \\
\hline & & No. $=56$ & No. $=32$ & \\
\hline \multirow{4}{*}{$\begin{array}{l}\text { Degree of } \\
\text { obstruction }\end{array}$} & No HN & $2(3.6 \%)$ & $0(0.0 \%)$ & \multirow{4}{*}{0.220} \\
\hline & Mild HN & $39(69.6 \%)$ & $23(71.9 \%)$ & \\
\hline & Moderate HN & $12(21.4 \%)$ & $4(12.5 \%)$ & \\
\hline & Marked HN & $3(5.4 \%)$ & $5(15.6 \%)$ & \\
\hline \multirow{2}{*}{$\mathrm{T} 1 / 2(\min )$} & Mean \pm SD & $13.53 \pm 5.06$ & $11.06 \pm 5.85$ & \multirow{2}{*}{0.041} \\
\hline & Range & $5-30$ & $4-30$ & \\
\hline \multirow{2}{*}{ increase in SRF\% } & Median(IQR) & $7(1.5-11)$ & $8(3.5-13)$ & \multirow{2}{*}{0.358} \\
\hline & Range & $-7-15$ & $-8-12.7$ & \\
\hline
\end{tabular}

Group 2 included 9 patient with SRF < $10 \%$. They showed significant improvement of SRF. Also the remaining
23 cases showed significant improvement without significant difference between them (Tables 2 and 3). 
OUTCOME OF PEDIATRIC PYELOPLASTY IN RENAL UNITS WITH...

Table (2): Improvement of SRF in group 2 in cases above and below initial SRF $<10 \%$

\begin{tabular}{|c|c|c|c|c|}
\hline \multicolumn{2}{|c|}{$\begin{array}{l}\text { Parameters } \\
\text { Cases with SRF }<10 \%\end{array}$} & Preoperative & Postoperative & P-value \\
\hline \multirow{2}{*}{$\mathrm{T} 1 / 2 \mathrm{~min}$} & Mean \pm SD & $19.33 \pm 4.53$ & $9.56 \pm 5.50$ & \multirow{2}{*}{0.000} \\
\hline & Range & $15-24$ & $4-18$ & \\
\hline \multirow{2}{*}{ SRF \% } & Mean \pm SD & $6.21 \pm 2.26$ & $15.04 \pm 7.09$ & \multirow{2}{*}{0.012} \\
\hline & Range & $3-9.9$ & $0-18.7$ & \\
\hline \multicolumn{2}{|c|}{$\begin{array}{l}\text { Parameters } \\
\text { Cases with SRF10-20\% }\end{array}$} & Preoperative & Postoperative & P-value \\
\hline \multirow{2}{*}{ SRF \% } & Mean \pm SD & $15.74 \pm 2.30$ & $23.07 \pm 6.75$ & \multirow{2}{*}{0.000} \\
\hline & Range & $11-19$ & $10-33$ & \\
\hline
\end{tabular}

Table (3): Improvement of SRF in cases above and below $10 \%$

\begin{tabular}{|l|c|c|c|}
\hline \multirow{2}{*}{ Split \% } & $\mathbf{0 - 1 0 \%}$ & $\mathbf{1 1 - 2 0 \%}$ & \multirow{2}{*}{ P-value } \\
\cline { 2 - 3 } Increase in SRF & No. =9 & No. $=\mathbf{2 3}$ & \multirow{2}{*}{0.355} \\
\hline Median (IQR) & $12.7(4-14)$ & $6(2-13)$ & \\
\hline Range & $-8-17$ & $-6-17$ & \\
\hline
\end{tabular}

In our study, we observed that only shown more increase in SRF than preoperative variable to have effect on improvement of SRF was mode of asymptomatic one. This occurred either in presentations. Symptomatic cases were all cases or in group 1 and group 2 (Table 4).

Table (4): Comparison of presentation versus improvement of SRF\% and T1/2 in all cases

\begin{tabular}{|l|c|c|c|c|}
\hline \multirow{2}{*}{ Improvement } & Cases & Asymptomatic & Symptomatic & \multirow{2}{*}{ P-value } \\
\cline { 3 - 5 } & & No. $=\mathbf{4 8}$ & No. $=\mathbf{4 0}$ & \\
\hline increase in SRF\% & Median(IQR) & $4(0-6.5)$ & $13(10-16)$ & 0.000 \\
\hline \multirow{2}{*}{ Group 1 } & Improvement & Asymptomatic & Symptomatic & \multirow{2}{*}{ P-value } \\
\cline { 4 - 5 } & & No. = 33 & No. = 23 & \\
\hline increase in SRF\% & Median(IQR) & $3(0-6)$ & $11(10-14)$ & 0.001 \\
\hline \multirow{2}{*}{ Group 2 } & Improvement & Asymptomatic & Symptomatic & \multirow{2}{*}{ P-value } \\
\cline { 3 - 4 } & & No. = 15 & No. $=\mathbf{1 7}$ & \\
\hline increase in SRF\% & Median(IQR) & $4(2-7)$ & $13(9-16)$ & 0.018 \\
\hline
\end{tabular}

Among symptomatic cases, most of cases and in group 1 and group 2 them improved by $\geq 5 \%$. This was in all separately (Table 5).

Table (5): Relation between mode of presentation and degree of improvement of SRF\%

\begin{tabular}{|l|c|c|c|c|c|c|}
\hline \multirow{2}{*}{ Improvement } & \multicolumn{2}{|c|}{$<\mathbf{5 \%}$} & \multicolumn{2}{|c|}{$\geq \mathbf{5 \%}$} & \multirow{2}{*}{ P-value } \\
\cline { 3 - 7 } Cases & No. & $\mathbf{\%}$ & No. & $\mathbf{\%}$ & \\
\hline \multirow{2}{*}{ All cases } & Asymptomatic & 25 & $89.3 \%$ & 22 & $39.3 \%$ & \multirow{2}{*}{0.001} \\
\cline { 2 - 7 } & Symptomatic & 3 & $10.7 \%$ & 34 & $60.7 \%$ & \\
\hline \multirow{2}{*}{ Group 1 } & Asymptomatic & 17 & $94.4 \%$ & 16 & $43.2 \%$ & \multirow{2}{*}{0.000} \\
\cline { 2 - 6 } & Symptomatic & 1 & $5.6 \%$ & 21 & $56.8 \%$ & \\
\hline \multirow{2}{*}{ Group 2 } & Asymptomatic & 8 & $80.0 \%$ & 6 & $31.6 \%$ & \multirow{2}{*}{0.013} \\
\cline { 2 - 6 } & Symptomatic & 2 & $20.0 \%$ & 13 & $68.4 \%$ & \\
\hline
\end{tabular}


Among symptomatic cases in group 2, the mean improvement in SRF was highly significant in cases presented with an abdominal swelling, while for cases presented with loin pain and antenatal diagnosed cases was significant, for accidentally discovered cases, improvement was not significant (Table $6)$.

Table (6): Improvement of SRF in different mode of presentation in group 2

\begin{tabular}{|c|c|c|c|}
\hline SRF\% & Preoperative & Postoperative & p-value \\
\hline Antenatal & $9.32 \pm 5.45$ & $14.96 \pm 3.25$ & 0.014 \\
\hline Loin pain & $14.4 \pm 3.18$ & $22.96 \pm 9.96$ & 0.011 \\
\hline Accidentally discovered & $16.79 \pm 2.04$ & $20.03 \pm 4.83$ & 0.084 \\
\hline Abdominal swelling & $9.98 \pm 5.48$ & $24.76 \pm 6.56$ & 0.000 \\
\hline
\end{tabular}

\section{DISCUSSION}

The traditional intervention for poorly functioning renal unit was nephrectomy but recently, there were studies which recommend pyeloplasty even with $\mathrm{SRF}<10 \%$ as these kidneys shows significant improvement (Lone et al., 2017). The definition of Poorly functioning kidneys show wide variability as we will discuss later on, we considered kidney is poorly functioning if $\mathrm{SRF} \leq$ $20 \%$. We included in our study not only the data for kidneys with less than $20 \%$ SRF but also included the group with SRF $>20 \%$ to see how renal units with SF close to the poorly functioning range behave.

In a study of Singh et al. (2013), percutaneous nephrostomy (PCN) tube used preoperatively in all patient in their study to detect chance of renal recovery, while in our study, PCN not used in any case, as the policy in our center to use PCN only in case of emergency such as pyonephrosis, single kidney or bilateral obstruction with elevated serum Creatinine, this point of view is in agree with Lone et al. (2017) in their study. Also PCN fixation in pediatric patient done under general anesthesia which represents an extra risk for patient, this point of view is in agree with Gnech et al. (2019) in their study.

In study by Bansal et al. (2012), they studied 39 patient with $\mathrm{SRF}<30 \%$ and divided them into two groups: group I (10-30\%) and Group II (<10\%). Mean preoperative renal function in group I was $24.7 \%$ (increased to $38.9 \%$ with mean increase was $14.2 \%$ and in group II was $5.1 \%$ (increased to $19 \%$ with mean increase was $13.9 \%$ ). Also in our study there were 9 cases with SRF $<10 \%$, mean preoperative SRF was $6.21 \pm 2.26 \%$ increased to $15.04 \pm 7.09$ with median increase was $12.7 \%$.Another study done by Lone et al.(2017), they studied 24 patients with $\mathrm{SRF} \leq 15 \%$, divide them into two groups: group A (15\%-11\%) and group B $(\leq 10 \%)$. The overall preoperative mean SRF was $10.61 \pm 5.23 \%$ increased in postoperative follow up to $18.08 \pm 7.3 \%$, $18.17 \pm 8.63 \%$ and $18.42 \pm 8.42 \%$ at 3 months, 9 months and 18 months respectively. Preoperative mean SRF in group A was $14.4 \pm 1.01 \%$ increased in postoperative follow up to $19.6 \pm 6.1 \%$ (pvalue 0.29 ) and in group B was $5.3 \pm 3.7 \%$ 
increased to $16.7 \pm 8.8 \%$ (p-value 0.03 ), so they concluded that in spite both group shows improvement, it was significant in group B and overall but not in group A, while in our study all cases in group 2 either with SRF $20-10 \%$ or with SRF< $10 \%$ showed significant improvement (from $15.74 \pm 2.30 \% 23.07 \pm 6.75, \mathrm{p}$ value 0.000 ) and (from $6.21 \pm 2.26$ to $15.04 \pm 7.09$ p-value 0.012 ) respectively.

Nayyar et al. (2016) studied 32 cases with split renal function $\leq 20 \%$. Thirteen patients $(40.6 \%)$ showed significant improvement in renal function, and in all, except $1(3.1 \%)$ case there was no further deterioration of function. Another study was done by Singh et al. (2013) showed Functional improvement in $24.1 \%$, no improvement in $44.8 \%$, deterioration in $31 \%$ of cases. Our study showed improvement in $63.6 \%$, preservation in $31.8 \%$ and deterioration in $4.6 \%$ of cases.

In a retrospective study done by Gnech et al. (2019), one case showed a postoperative SRF $47 \%$, starting from a $19 \%$ pre-operative SRF otherwise, the mean increase in the DRF was $3.5 \pm 9.8 \%$. Improvement $>5 \%$ was observed in 13 $(36 \%)$ cases, SRF remained unchanged in $16(45 \%)$ and 7 patients (19\%) showed deterioration in the SRF greater that 5\% compared with preoperative values. They compared the cases showed functional improvement greater than 5\% with the others; only a postnatal presentation was associated with a better improvement. When we saw the presentation of cases in this study, we observed that no cases discovered accidentally, so we can say all postnatal cases were presented by clinical signs and symptoms, so we can say that symptomatic cases in this study showed better improvement which is similar to observation in our study. Also in this study there in no significant difference in median age between improved and none improved group which is also similar to our study. In retrospective study done by Harraz et al. (2013), postoperative SRF had improved by greater than $5 \%$ in $49 \%$ of cases, while it was static at around 5\% in $23 \%$ of cases and deteriorated more than $5 \%$ in $28.1 \%$ of cases. Mean SRF significantly improved after pyeloplasty, increasing from $35.8 \% \pm 10 \%$ to $38.7 \% \pm 11 \%$ and . As stratified by baseline SRF, baseline SRF in the poor and intermediate groups improved, while in the good group SRF was static postoperatively .

In prospective study done by Menon et al. (2016), they studied 122 patients with UPJO and SRF<20\%, ten patients underwent nephrectomy so the final number of patient was 102 . They divided patients into group with SRF 0-9\% and group with SRF 10-20\% then subdivided both group into patient with clinical signs and symptoms and patient with asymptomatic presentation (antenatal diagnosis and incidentally discovered). They observed that highly significant mean increase in DRF was seen from 3.16 \pm 2.87 to $18.46 \pm 14.17 \%$ in the preoperative $0-9 \%$. and from $14.84 \pm 3.39$ to $23.71 \pm 10.48 \%$ in the $10-20 \%$ group , our result was nearly similar to this result, in patient with initial SRF 20-10\%, SRF increased from $15.74 \pm 2.30 \%$ to $23.07 \pm$ 6.75,( p-value 0.000) which is highly significant and in patient with initial SRF $<10 \%$, SRF increased from $6.21 \pm 2.26$ to $15.04 \pm 7.09$. which is significant. As regard relation between clinical presentation and improvement of SRF, 
they found that symptomatic patients improved better than asymptomatic patients, from $9.81 \pm 6.78$ to $22.25 \pm$ 11.42 , and (from 13.24 $\pm 4.18 \%$ to $21 \pm 12.7 \%$, respectively, which is also similar to our study. In their study patient presented with palpable mass and pain showed a highly significant . mean increase in DRF was seen from 8.14 $\pm 6.49 \%$ to $24.12 \pm 1.94 \%$ and $11.45 \pm 7.04$ \%to $19.54 \pm 10.48 \%$ respectively, which is also similar to our study mean increase of SRF for patients presented with abdominal swelling and loin pain in group 2 was from $9.98 \pm 5.48 \%$ to $24.76 \pm 6.56$. and from $14.4 \pm 3.18$ to $22.96 \pm 9.96$ respectively.

Another prospective study done by Abdelaziz et al. (2018), the median preoperative SRF was $5 \%$ increased to $21 \%$ and $20 \%$ after six months and one year respectively. They observed that mean improvement in SRF was high in cases presented with a palpable mass, median increased from $2 \%$ to $21 \%$, which is similar to our study, mean increase of SRF for patients presented with abdominal swelling in group 2 was from $9.98 \pm 5.48 \%$ to $24.76 \pm 6.56$ (.

\section{CONCLUSION}

From previously mentioned data, we can conclude that poorly functioning renal unit with $\mathrm{SRF}<20 \%$, can show functional improvement and recoverability, and these renal units behaves similarly to that one with SRF > 20\%.So in these renal units, we should not have to rush to nephrectomy and instead of that we can proceed to pyeloplasty.

\section{REFERENCES}

1. Abdelaziz AY, Shaker H, Aly H, Aldaqados $H$ and Hussein EM (2018): Early outcome of pediatric pyeloplasty in kidneys with split renal function less than 10\%: A prospective study of 25 cases. African J Urol., 24:324-330.

2. Bansal R., Ansari M.S., Srivastava A. and Kapoor R. (2012): Long-term results of pyeloplasty in poorly functioning kidneys in the pediatric age group. J Pediatr Urol., 8: 2528.

3. Dindo D, Demartines $\mathbf{N}$ and Clavien PA. (2004): Classification of surgical complications: a new proposal with evaluation in a cohort of 6336 patients and results of a survey. Ann Surg, 240: 205.

4. Fernbach SK, Maizels M and Conway JJ (1993): Ultrasound grading of hydronephrosis: introduction to the system used by the Society forFetal Urology. Pediatr Radiol., 23:478-80.

5. Gnech M., Berrettini A., Lopes R.I., Moscardi P., Esposito C., Zucchetta P., Dénes F.T., Manzoni G., Braga L.H. and Castagnetti M. (2019): Pyeloplasty vs. nephrectomy for ureteropelvic junction obstruction in poorly functioning kidneys (differential renal function <20\%): a multicenteric Study. J Pediatr Urol. doi:10.1016/j.jpurol.2019.05.032. [Epub ahead of print].

6. Harraz AM, Helmy T, Taha DE, Shalaby I, Sarhan O, Dawaba M and Hafez AT (2013): Changes in differential renal function after pyeloplasty in children. J Urol., 190: 1468-1473.

7. Kim J, Hong S, Park CH, Park $H$ and Kim KS. (2010): Management of severe bilateral ureteropelvic junction obstruction in neonates with prenatally diagnosed bilateral hydronephrosis. Korean J Urol., 51:653-656.

8. Lone YA, Samujh R, Bhattacharya A and Kanojia RP. (2017): Outcome of poorly functioning kidneys secondary to PUJO preserve.d by pyeloplasty. J Pediatr Surg., 52:578-81. 
9. Menon P, Rao KL, Bhattacharya $A$ and Mittal BR (2016): Outcome analysis of pediatric pyeloplasty in units with less than $20 \%$ differential renal function. J Pediatr Urol., 12:171.e1-e7.

10. Nayyar R, Yadav S, Singh P, Kumar R, Seth A and Dogra PN (2016): Outcomes of pyeloplasty in very poorly functioning kidneys: examining the myths.urology., 92:132-135.
11. Radmayer C, Bogaert G, Dogan HS, Ko?cvara R., Nijman J.M., Stein R. and Tekgül S. (2019): Guidelines on Paediatric Urology, European Society for Paediatric Urology, 12:56.

12. Singh A., Bajpai M., Panda S.S. and Sharma N. (2013): Role of percutaneous nephrostomy in poorly functioning kidney due to pelviureteric junction obstruction in older children.J Pediatr Urol., 16: 46-49 


\section{نتائج تجميل حوض الكلى فى الأطفال فى الوحدات الكلوية

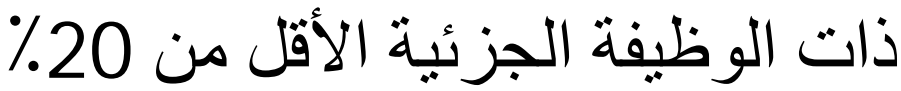

جمال إبر اهيم سلمى*ـ السيد محمد صالح*- محسن صلاح الدين ذكرى*** إبراهيم عبد

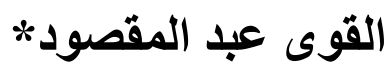

قسم جراحة المسالك البولية * والطب النووى**، كلية الطب، جامعة الأزهر

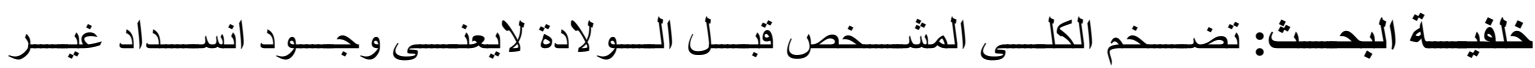

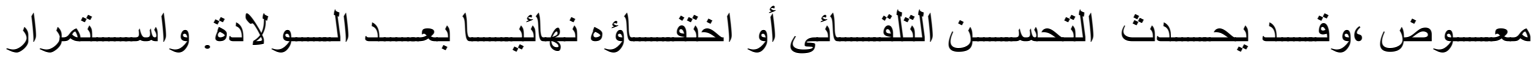

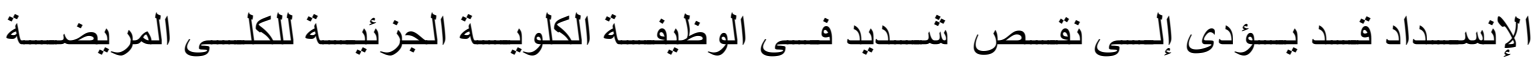
ويصبح التدخل الجراحى ضرورياً.

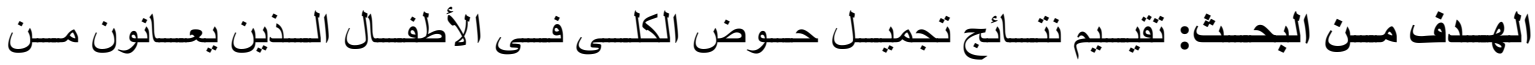

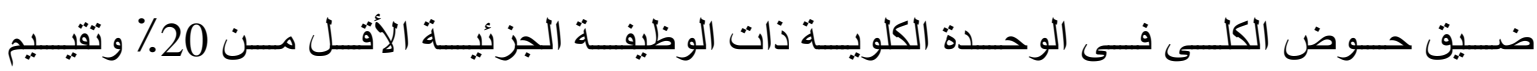

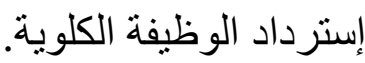

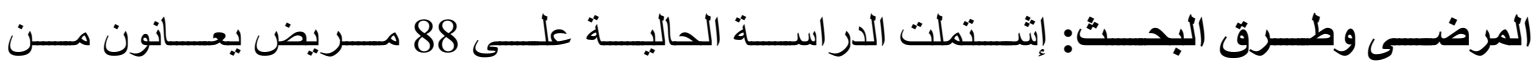

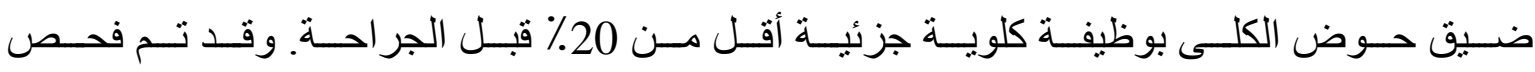

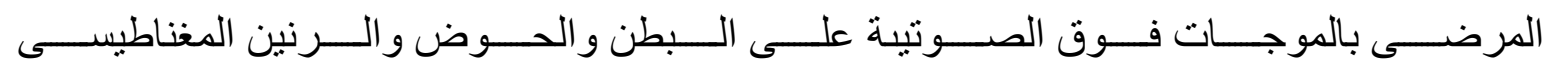

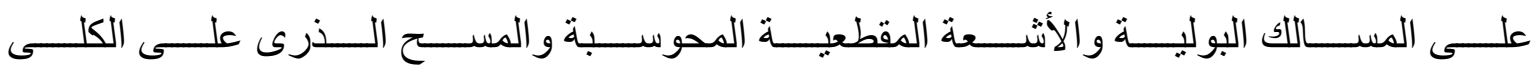

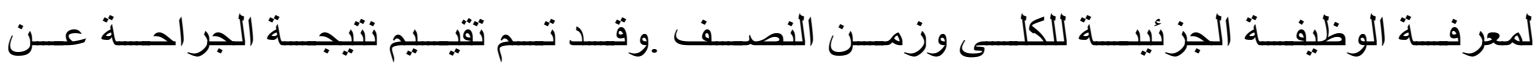

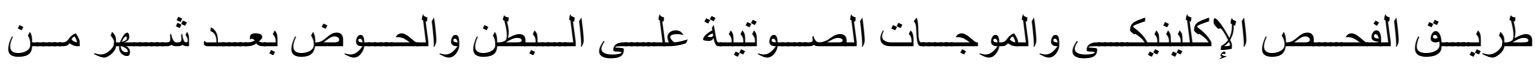
الجر احة وعن طريق المسح الذرى على الكلى بعد ستة أثشر.

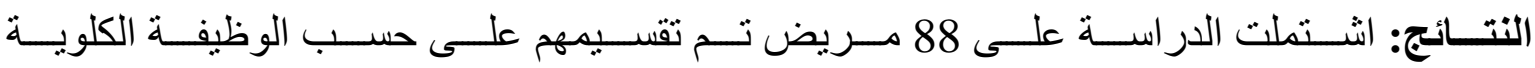

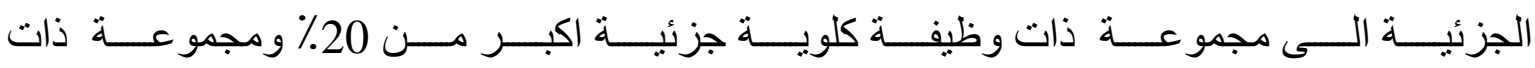

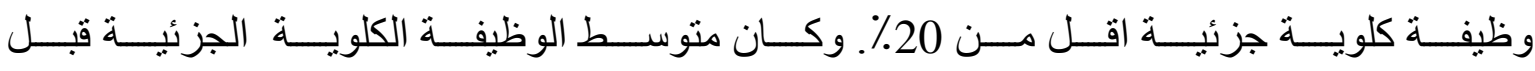

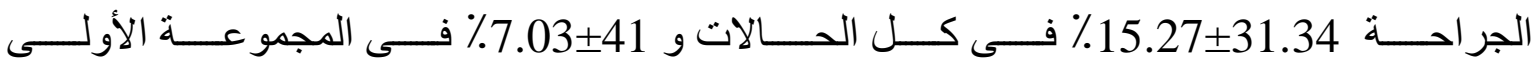

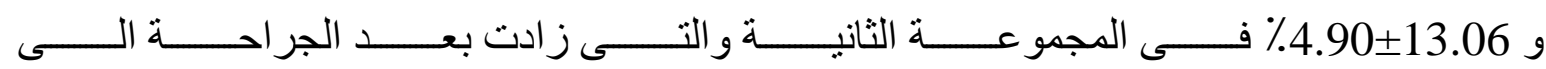

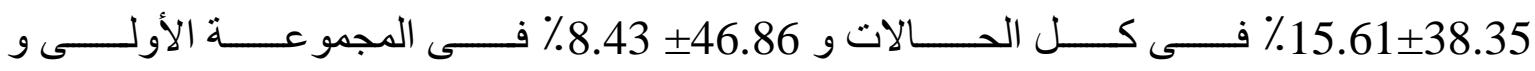




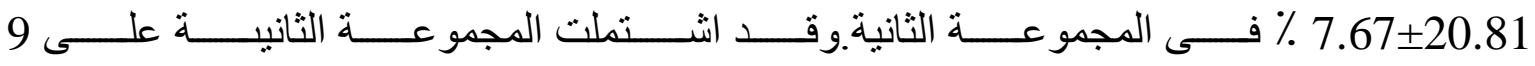

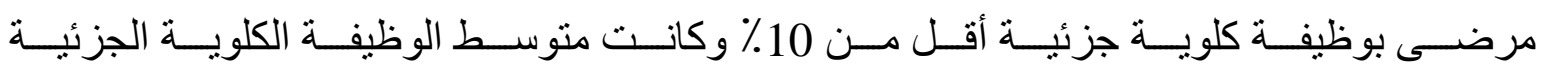

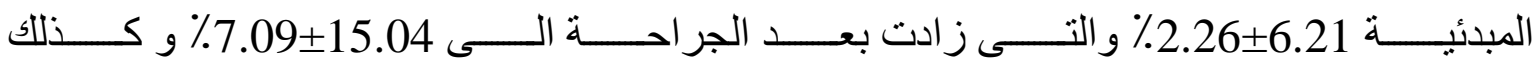

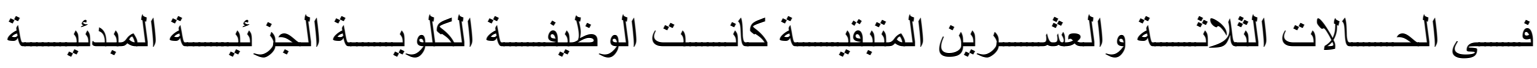
6.74 15.74 و التى زادت بعد الجراحة الى 23.07.

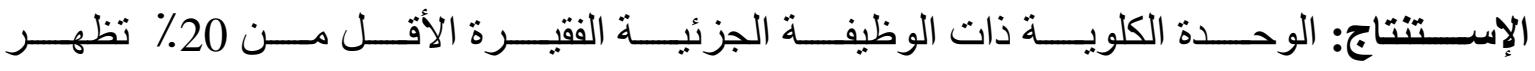
تحسنا واستردادا للوظيفة. 